\title{
Cardiovascular Disease and Hair Cortisol: a Novel Biomarker of Chronic Stress
}

\author{
Eleonora lob ${ }^{1} \cdot$ Andrew Steptoe ${ }^{1}$ \\ Published online: 30 August 2019 \\ (C) The Author(s) 2019
}

\begin{abstract}
Purpose of Review This review focuses on the concentration of cortisol in human hair as a biomarker of chronic stress in cardiovascular disease (CVD). We outline the cardiovascular consequences of cortisol excess and provide a comprehensive overview of recent studies investigating the relationship of hair cortisol with CVD. In addition, clinical implications and limitations of the evidence are discussed, together with directions for future research.

Recent Findings Hair cortisol may be a reliable biomarker of chronic stress since it provides quantification of total cortisol secreted into hair over several weeks. A growing body of evidence suggests that elevated hair cortisol levels are associated with both the incidence of CVD and poorer recovery and treatment outcomes. Moreover, increased hair cortisol concentration has been linked with established cardiometabolic risk factors for CVD including high blood pressure, diabetes, and adiposity.

Summary Hair cortisol is a promising biomarker of chronic cortisol excess which may contribute to both the pathogenesis and prognosis of CVD. However, the current evidence relies on small-scale cross-sectional studies. Further research adopting longitudinal designs across larger samples of CVD patients and healthy participants is required to inform the development of novel evidence-based interventions.
\end{abstract}

Keywords Chronic stress $\cdot$ Hair cortisol $\cdot$ Cardiovascular disease $\cdot$ Cardiometabolic markers

\section{Introduction}

Cardiovascular disease (CVD) is a leading contributor to the burden of morbidity and mortality across the world. Although the prevalence of CVD has declined significantly over the last two decades in many countries [1], cardiovascular conditions such as coronary heart disease and stroke remain the two most common causes of disease worldwide according to Global Burden of Disease and World Health Organization estimates $[2,3]$. Moreover, the levels of CVD-related deaths and years

This article is part of the Topical Collection on Psychological Aspects of Cardiovascular Diseases

Eleonora Iob

eleonora.iob.17@ucl.ac.uk

Andrew Steptoe

a.steptoe@ucl.ac.uk

1 Department of Behavioural Science and Health, University College London, UCL, Gower Street, London WC1E 6BT, UK lost due to ill health or premature death have increased considerably since 2006 owing to population growth and ageing. Hence, the identification of modifiable risk factors and novel targets for preventive interventions is an issue of major public health concern.

Established cardiometabolic risk factors which are known to substantially increase CVD risk include elevated cholesterol levels [4], high blood pressure [5], excessive weight gain and obesity [6] and diabetes [7]. Whilst strong effects have been found for cigarette use [8], the contribution of other behavioural factors such as physical inactivity and alcohol consumption appears less consistent $[9,10]$. Recently, greater attention has been devoted to the role of psychosocial stress in CVD as a result of increasing knowledge of its adverse physiological consequences for both mental and physical health [11]. A significant body of evidence indicates that acute and chronic stressors (e.g. childhood trauma, work stress, social isolation) and negative emotional states (e.g. depression, anxiety) can influence the development of CVD and triggering of cardiovascular events independently of classical CVD risk factors [12-15]. The elevated CVD risk associated with a 
history of multiple stressful events during childhood is comparable to that observed for several cardiometabolic and behavioural risks [12]. Adult stress appears to have a more influential role in the triggering of cardiovascular events rather than in the aetiology of the disease [16••]. Psychosocial stress also acts as a prognostic factor contributing to the course, progression, and outcomes of CVD [17-20]. Additionally, conventional risk factors for CVD including hypertension [21], diabetes [22], adiposity [23], smoking [24], and physical inactivity [25] are negatively affected by stress.

The relationship between psychosocial stress and CVD is now well documented in the epidemiological and clinical research literature. Yet, the psychobiological processes through which stress contributes to the pathogenesis and prognosis of CVD remain elusive. Dysregulation of the hypothalamicpituitary-adrenal (HPA)-axis has been proposed to underlie the adverse physiological effects of stress on CVD [16••]. Traditionally, HPA-axis function has been measured through the assessment of cortisol levels in saliva, blood, or urine. However, the concentration of cortisol secreted into hair has recently emerged as a novel biomarker of long-term HPA-axis activity offering several advantages over traditional specimens [26]. This review focuses on the role of hair cortisol as a biomarker of chronic stress in CVD. First, the cardiovascular effects of chronic cortisol exposure are described. Second, we discuss the main limitations of cortisol measurements in body fluids (i.e. saliva, blood, and urine) and outline key advantages of cortisol quantification in human hair. Third, we provide a comprehensive overview of emerging studies investigating the association of hair cortisol with CVD incidence, prognosis and cardiometabolic risk factors. Lastly, clinical applications, limitations of the current evidence and directions for future research are discussed.

\section{The Role of Chronic Exposure to Cortisol in CVD}

\section{Physiology of the Stress Response}

The HPA-axis is a crucial stress response system in humans. Its primary function is to maintain homeostasis and facilitate successful adaptation to the surrounding environment [27]. This is achieved through a cascade of hormonal reactions involving the hypothalamus, the pituitary gland and the adrenal cortex [28] (Fig. 1). The activation of the stress response begins with the release of corticotropin releasing factor (CRF) and vasopressin (AVP) from the hypothalamus. Increased levels of these hormones stimulate the production of adrenocorticotropic hormone (ACTH) from the pituitary gland. This in turn prompts the adrenal gland to release glucocorticoids including cortisol, the primary end-product of the HPA- axis [28]. Glucocorticoids are transported into the blood stream by corticosteroid binding globulin $(\mathrm{CBG})$ and readily diffuse through cellular membranes by binding to both mineralocorticoid receptors (MR) and glucocorticoid receptors (GR) [29].

Acute and transient HPA-axis activation has an adaptive function since it facilitates effective coping with external stressors by triggering a number of physiological reactions. These include, for instance, increased vascular tone, immune activation, suppression of inflammation, energy mobilisation, insulin resistance, inhibition of reproductive physiology and behaviour and sharpened cognition [30]. However, prolonged and repeated cortisol exposure is maladaptive and may lead to long-term physiological alterations compromising the function of the cardiovascular, metabolic, immune and nervous systems [11]. Consequently, chronic stress may increase the individual's susceptibility to poor health and disease.

\section{Cardiovascular Consequences of Chronic Cortisol Excess}

The unfavourable effects of chronic cortisol excess on the body and the brain are particularly relevant for the pathogenesis and progression of CVD. Details of the impact of chronic cortisol excess on the development of CVD are beyond the scope of this review, but include hyperlipidaemia, insulin resistance, hyperglycaemia, hypertension and abdominal adiposity [29, 31] (Fig. 1). Briefly, elevated glucocorticoid output can affect plasma lipoprotein metabolism resulting in elevated levels of cholesterol and triglycerides. Cortisol opposes the action of insulin and activate gluconeogenesis in the liver thereby contributing to insulin resistance and hyperglycaemia [29]. Elevated glucocorticoids are known to have harmful effects on blood pressure and lead to hypertension. Candidate mechanisms in the development of cortisolinduced hypertension include mineralocorticoid-induced sodium retention, plasma volume expansion, and inhibition of vasodilator hormones [31]. Moreover, increased glucocorticoid output is linked with a number of metabolic changes, such as greater adipocyte development and increased $11 \beta$-hydroxysteroid dehydrogenase I (HSD11B1) activity in adipocytes, which can augment visceral adiposity and risk of abdominal obesity. In turn, increased adiposity contributes to other CVD risk factors since fat cells release hormones and metabolites that adversely affect blood pressure, plasma lipoproteins, coagulation and insulin resistance [29].

Cortisol has a direct impact on the heart and blood vessels as well as systemic effects on cardiometabolic markers [32]. GR and MR are expressed in the circulatory system where glucocorticoids are involved in the 


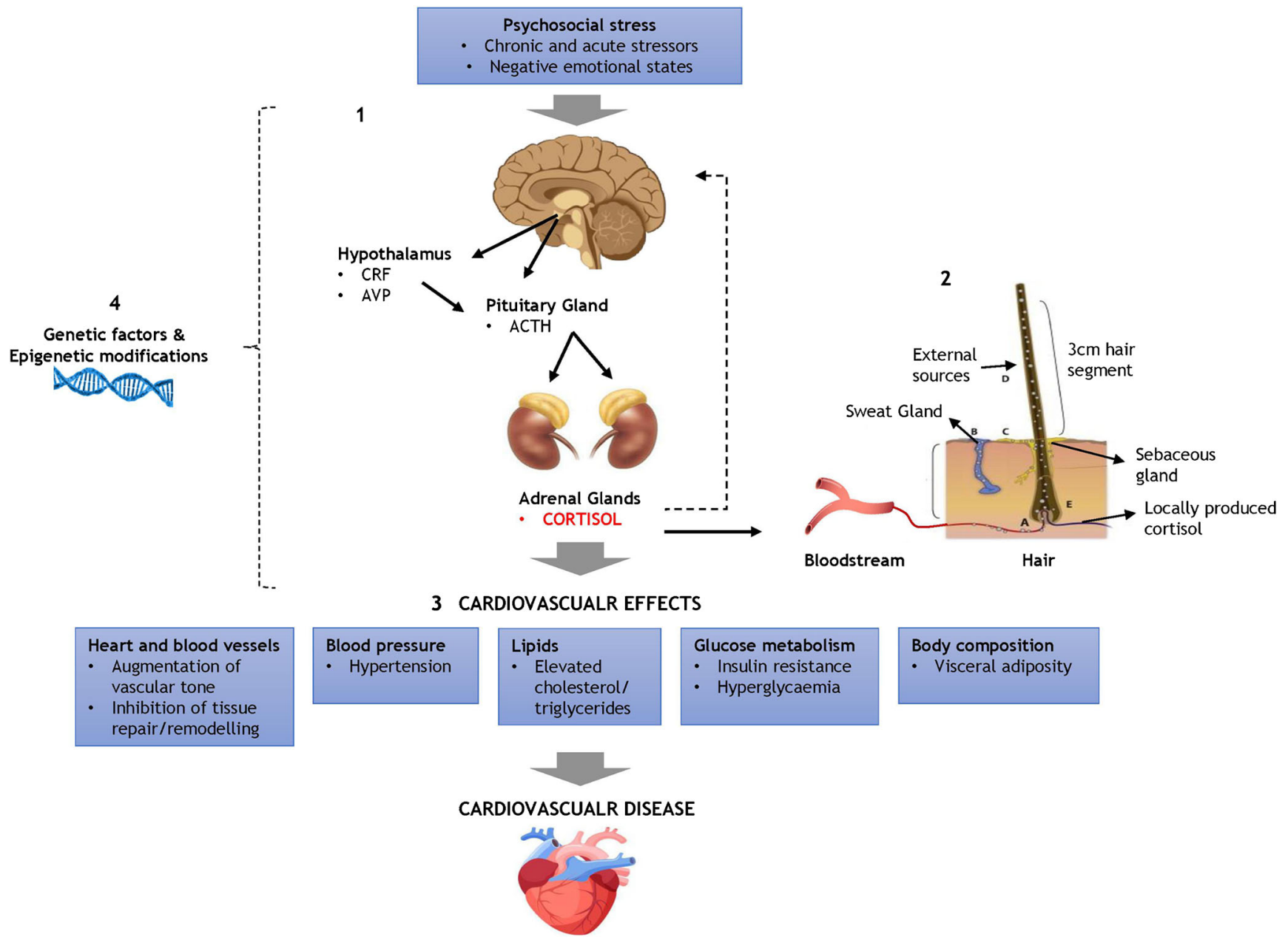

Fig. 1 Mechanisms through which psychosocial stress leads to elevated hair cortisol concentration and affects cardiovascular disease (CVD) risk and prognosis. $1 \mathrm{HPA}$-axis response to psychosocial stress. 2

maintenance of vascular tone and in the modulation of inflammatory, proliferative and remodelling responses to injury and vascular occlusion [33]. Such local effects have been proposed to play an important role not only in the process of atherogenesis but also in the progression of CVD [32].

Compelling evidence for the adverse cardiovascular consequences of chronic cortisol excess has been provided by studies of patients with endogenous hypercortisolism and those treated with glucocorticoid therapy. For instance, patients with Cushing's syndrome, a condition characterised by chronic cortisol excess, are estimated to have a fourfold higher risk of CVD mortality, higher rates of CVD complications, and greater incidence of cardiometabolic risk factors (e.g. obesity, hypertension, insulin resistance) compared to healthy controls [31, 34, 35]. Likewise, patients treated with high doses of glucocorticoids have been shown to have substantially higher risk of cardiovascular events and adverse cardiometabolic markers $[32,36]$.
Incorporation of cortisol into hair. 3 Cardiovascular effects of cortisol. 4 Role of genetic factors and epigenetic processes. (Hair image adapted from Stalder \& Kirschbaum, 2012) [26]

\section{Methods for Assessing Cortisol Levels}

\section{Measurement of Cortisol in Blood, Urine, and Saliva}

Given the elevated CVD risk observed in patients with Cushing's syndrome and those treated with glucocorticoid therapy, several studies have investigated the relationship of endogenous cortisol levels with the development and progression of CVD in both clinical and population-based samples. Endogenous cortisol levels have traditionally been assessed through measurements in body fluids including saliva, blood and urine [37]. Blood samples provide measures of circulating levels of both CBG-bound and bioactive (free) cortisol at a single time point. In contrast, urinary measures of cortisol reflect the total exposure to bioactive cortisol across 12 or $24 \mathrm{~h}$ [38]. Bioactive cortisol levels can also be measured via saliva samples. However, as for blood samples, salivary cortisol only provides quantification of cortisol concentration at a single time point [37]. Since cortisol has a marked diurnal rhythm, multiple blood or saliva samples over the day are 
needed to characterise the overall profile of cortisol secretion. Repeated blood sampling is difficult to carry out except in clinical or laboratory settings, so saliva has been increasingly favoured as less obtrusive. These methods are particularly useful in acute laboratory stress paradigms for monitoring acute HPA-axis responses [39].

Overall, this work has provided evidence that cortisol dysregulation is associated with CVD incidence [40-44], prognosis $[45,46]$ and mortality $[47,48]$, as well as with cardiometabolic risk factors such as hypertension, hyperlipidaemia, hyperglycaemia and diabetes [49-56]. However, not all studies have found evidence supporting this link [49, 57-62], and some have reported reduced HPA-axis activity [63-66]. Additionally, there is little agreement on the types of cortisol measures that might be more predictive of CVD risk and progression across studies.

These inconsistent results could be explained by the limitations of cortisol quantification in body fluids. A fundamental issue with these methods is that they only provide momentary or short-term estimates of cortisol levels, rather than information on long-term exposure to elevated cortisol [26]. Cortisol concentration in saliva, blood and urine is also subject to several situational and interindividual fluctuations due to various confounding factors such as circadian rhythm, momentary moods and events and study procedures. Few studies take samples over several days, and the days selected may not be representative. The collection of repeated cortisol measures over the course of a day can lead to excessive participant burden and incomplete sample collection [67]. Crucially, prolonged and repeated exposure to elevated cortisol levels is likely to play a more important role in the aetiology and progression of CVD than acute and short-term cortisol reactivity. Indeed, acute and transient cortisol exposure is typically unharmful and promotes successful adaptation to the environment. In contrast, chronically elevated cortisol levels are maladaptive and related to ill health $[68 \cdot \bullet]$.

\section{Hair Cortisol: a Novel Biomarker of Chronic Cortisol Exposure}

Since the discovery of glucocorticoids in hair in 2004 [69], several lines of research have suggested that hair cortisol is a valid biomarker of psychosocial stress in both children and adults [67, 70-73]. Quantification of cortisol in hair offers several advantages over traditional specimens. In particular, hair cortisol may be a reliable biomarker of long-term HPA-axis activity since it reflects total cortisol output over several weeks or months. Hair analysis also offers a non-invasive, lowburden and single-sample measurement of HPA-axis activity which does not rely on participant adherence to collection instructions. Additionally, hair cortisol concentration is less influenced by situational and interindividual variations than traditional methods and has high test-retest reliability [26, 38]. Hence, hair cortisol may prove to be a suitable biomarker for studying the cardiovascular consequences of chronic stress in both clinical settings and large-scale population studies.

Incorporation of cortisol into hair may occur through a number of mechanisms (Fig. 1). It has been suggested that the free cortisol present in follicular capillaries is incorporated into the medulla of the hair shaft via passive diffusion during hair growth. Thus, the amount of cortisol deposited into hair is likely to reflect biologically active hormone [38], and to be proportional to the concentration of systemic cortisol [74]. It has also been proposed that cortisol is deposited onto the hair shaft through sweat and sebaceous glandular secretions [69]. Additionally, a local HPA-like pathway in the hair follicles has been suggested [75]. The extent to which these different sources contribute to hair cortisol content remains unclear.

While there are some individual and ethnic variations, human hair is generally estimated to grow approximately $1 \mathrm{~cm}$ per month [76]. Segmental hair analysis therefore provides the opportunity to use cortisol content in each centimetre of hair as a proxy measure of HPA-axis activity during the month represented by the respective hair segment [67]. Unfortunately, cortisol can only be reliably estimated in the $6 \mathrm{~cm}$ closest to the scalp because more distal hair segments contain lower hormone levels due to greater environmental damage [76]. Concentrations of cortisol in hair are affected by repeated shampooing, chemical treatments (e.g. demi-perms, bleach) and sun exposure, so these factors need to be taken into account $[77 \bullet \bullet$. The posterior vertex has been shown to have less variation in cortisol levels than other areas of the scalp [78]. Consequently, most studies typically collect a $3-\mathrm{cm}$ segment of hair from the posterior vertex as close to the scalp as possible in order to represent total cortisol output over the preceding 3 months [67]. After collection, hair samples are typically weighted, washed and either minced or grounded. Cortisol is then extracted from minced or ground hair using organic solvents. Finally, the extracted cortisol is quantified using an immunoassay or liquid chromatography tandem-mass spectrometry (LC-MS/ MS) [74]. Although their agreement in terms of absolute values is low, correlations between cortisol levels determined by these two methods are generally high [79]. It should be noted that the absolute concentration of cortisol is very different in hair, blood, saliva and urine, so each system has its own distribution and range. 
Research Evidence for the Relationship of Hair Cortisol with CVD

\section{Association of Hair Cortisol with CVD Incidence and Prognosis}

A systematic search of all published studies up to May 2019 using PubMed, Ovid Medline and Web of Science revealed 11 studies examining the association of hair cortisol with the incidence or recovery from CVD (Table 1). Four casecontrol studies found evidence for higher hair cortisol levels in patients with acute coronary syndrome [80 $]$, myocardial infarction $\left[81^{\bullet}\right]$, coronary heart disease $\left[83^{\circ}\right]$ and aneurysmal subarachnoid haemorrhage [82•] compared with control participants. In addition, a population-based study revealed that higher hair cortisol was associated with an increased incidence of coronary heart disease, stroke and peripheral arterial disease [84•]. In contrast, coronary heart disease diagnosis or the experience of a stroke were unrelated to hair cortisol in a large observational cohort [85.]. However, hair cortisol was positively associated with other CVD risk factors (i.e. BMI, diabetes) and CVD medication in this study, and the authors suggest that hair cortisol might be more predictive of CVD risk rather than being an actual marker of CVD.

Hair cortisol concentration has also been investigated as a prognostic factor in CVD. One study revealed a positive relationship between hair cortisol and the severity of symptoms in a sample of patients with chronic heart failure [86•]. Over a 1-year follow-up, there also was a positive albeit non-significant trend towards higher hair cortisol in patients who had CVD-related hospitalisations compared with non-hospitalised patients. Elevated hair cortisol levels predicted poorer memory improvement in a sample of patients with coronary artery disease attending a 1-year cardiac rehabilitation intervention [87॰], while another study demonstrated that higher hair cortisol concentration was associated with larger lesion volume and worse cognitive results 6,12 and 24 months following stroke [88•]. Elevated hair cortisol has also been associated with greater psychological distress in patients with aneurysmal subarachnoid haemorrhage [82•]. Another study found that higher hair cortisol concentration was related to worse subjective physical health status in patients with structural heart disease (cardiomyopathy, congenital heart disease or coronary heart disease), while a more favourable mental health status predicted a decline in cortisol levels at 12week follow-up [90•]. By contrast, another study of patients with acute coronary syndrome found no evidence supporting the link between hair cortisol and depressive symptoms [89].

\section{Association of Hair Cortisol with Cardiometabolic Risk Factors}

A larger number of studies have investigated the relationship of hair cortisol with cardiometabolic risk factors. Table 2 provides an overview of the evidence available to date. A metaanalysis of 11 studies has corroborated the positive association

Table 1 Association of hair cortisol with the incidence and prognosis of CVD

\begin{tabular}{|c|c|c|c|c|c|}
\hline Factors & & Significant association & Sample Size & Duration & Refs \\
\hline \multicolumn{6}{|l|}{ CVD incidence } \\
\hline \multicolumn{6}{|l|}{ Condition } \\
\hline Acute coronary syndrome & & Yes & 166 & Cross-sectional & {$[80 \bullet$} \\
\hline Acute myocardial infarction & & Yes & 112 & Cross-sectional & [81•] \\
\hline Aneurysmal subarachnoid haemorrhage & & Yes & 32 & Cross-sectional & [82•] \\
\hline Coronary heart disease & & Yes & 598 & Cross-sectional & [83•] \\
\hline Coronary heart disease/stroke/peripheral arterial disease & & Yes & 283 & Cross-sectional & [84•] \\
\hline Coronary heart disease/stroke & & No & 3675 & Cross-sectional & {$[85 \bullet]$} \\
\hline \multicolumn{6}{|l|}{ CVD prognosis } \\
\hline Condition & Outcome/predictor & & & & \\
\hline Chronic heart failure & Symptom severity & Yes & 44 & Prospective & {$[86 \bullet$} \\
\hline Coronary artery disease & Recovery & Yes & 56 & Prospective & {$[87 \cdot]$} \\
\hline Stroke & Recovery & Yes & 65 & Prospective & {$[88 \bullet]$} \\
\hline Acute coronary syndrome & Psychological distress & No & 121 & Cross-sectional & [89] \\
\hline Aneurysmal subarachnoid haemorrhage & Psychological distress & Yes & 32 & Cross-sectional & {$[82 \cdot]$} \\
\hline Structural heart disease & Psychological distress & Yes & 261 & Prospective & {$[90 \bullet]$} \\
\hline Structural heart disease & Physical health status & Yes & 261 & Cross-sectional & {$[90 \bullet$} \\
\hline
\end{tabular}


of hair cortisol with systolic blood pressure, whereas the relationship with diastolic blood pressure was overall nonsignificant [68••]. Elevated hair cortisol levels have also been related to adverse metabolic blood markers such as cholesterol, triglycerides and glycated haemoglobin [91-93, 95], although associations were not significant in all cases [94]. Thus, the relationship of hair cortisol with lipids varied considerably across studies. Two studies calculated a composite score of cardiometabolic risk based on the diagnostic criteria for the metabolic syndrome which was found to be positively associated with hair cortisol [91, 93]. Moreover, virtually all studies to date have confirmed the presence of elevated hair cortisol levels in people with diabetes [84, 85, 96-98]. Robust effects have also been reported for the link between hair cortisol and adiposity, and a meta-analysis confirmed the association with higher body mass index (BMI) and waist-hip ratio [68]. Interestingly, there is evidence suggesting that hair cortisone is linked with unfavourable cardiometabolic markers, and these associations are sometimes stronger than those for cortisol [91, 93, 94]. Cortisone is another glucocorticoid hormone which is directly metabolised from cortisol by HSD11B enzymes. It is generally considered to be an inactive metabolite since it has considerably lower glucocorticoid activity than cortisol [69]. Therefore, the assessment of hair cortisone along with cortisol could provide greater insight into long-term levels of both active and inactive glucocorticoids in the body $[77 \cdot \bullet]$. Overall, despite the presence of some inconsistent findings, current research provides intriguing evidence for the adverse cardiometabolic effects of chronic cortisol excess as assessed in human hair.

\section{Clinical Applications}

Hair cortisol may be valuable not only in understanding the development and prognosis of CVD, but also in prevention and treatment. However, the impact of psychosocial, behavioural and pharmacological interventions on long-term cortisol levels is not yet known. The potential benefits for CVD of psychosocial treatment focusing on stress management have been demonstrated in several investigations [16••]. A Cochrane review of 35 studies published in 2017 concluded that psychosocial treatment might lead to reduced cardiovascular mortality among people with coronary heart disease, but noted that many trails have been of low quality and do not provide robust data [99]. On the other hand, studies on the general population indicate that psychosocial interventions such as cognitive behavioural therapy (CBT), mindfulness, yoga or green space exposure are associated with reductions in cortisol levels and other stress-related hormones, as well as with a more favourable cardiometabolic risk profile [100-103]. In addition, it has been suggested that pharmacological therapy reducing glucocorticoid exposure could have a beneficial action on the pathogenesis and progression of $\mathrm{CVD}$ $[32,104]$. However, there is as yet no direct evidence supporting the efficacy of interventions reducing chronic cortisol levels for the prevention and treatment of CVD.

There is a small number of studies incorporating hair cortisol into intervention studies. For instance, hair analysis has been included in a mindfulness trial for smoking cessation. This study compared the hair segment corresponding to the pre-intervention period to that indexing the post-intervention phase and demonstrated a significant decrease in cortisol concentration after the mindfulness intervention [105]. Another randomised controlled trail of 151 patients with structural heart disease who underwent either mindfulness training or CBT showed a significant decrease in hair cortisol after the intervention in both groups [90•]. These findings highlight the potential of hair cortisol to strengthen the evidence for the effectiveness of different types of stress reduction interventions for CVD.

\section{Open Questions and Future Directions}

The research literature on hair cortisol and CVD is still in its infancy. Although the results are promising, the evidence presented in this review is predominantly based on small-scale cross-sectional studies. Larger prospective studies including repeated assessments of hair cortisol and CVD are required in order to obtain estimates that are more robust and clarify the direction of associations. Furthermore, new intervention studies are needed to test the effectiveness of psychosocial and medical interventions that reduce cortisol levels in the long term. Such work will provide stronger evidence for the possible casual effect of chronic stress on CVD and inform the development of novel preventive and treatment strategies. A number of limitations should be noted. Some people are reluctant to provide hair samples, and baldness or lack of sufficient hair becomes more common with increasing age. Hair assessment is also not suitable for the study of short-term cortisol response to stress or transient clinical events.

This review has only focused on the effect of stress on long-term cortisol levels and CVD. However, elevated cortisol levels could also result from unhealthy behaviours such as smoking [92], excessive alcohol consumption [84•] and physical inactivity [106]. Psychosocial stress may have both a direct effect on CVD and an indirect relationship mediated by health behaviours [107], although studies relating lifestyle factors with hair cortisol have produced inconsistent results [68・•, 85•, 96].

Recent developments in genotyping methods and the availability of large-scale genetic consortia will increase our knowledge of the role of genetic and epigenetic factors in the relationship between cortisol and CVD. Certain individuals might be more susceptible to stress-induced CVD owing 
Table 2 Association of hair cortisol with cardiometabolic risk factors for CVD

\begin{tabular}{|c|c|c|c|c|}
\hline Risk factors & Significant association & Sample Size & Duration & Ref \\
\hline Diastolic blood pressure & No & $2832^{\mathrm{b}}$ & Cross-sectional & {$[68 \bullet \bullet$} \\
\hline Systolic blood pressure & Yes & $2832^{\mathrm{b}}$ & Cross-sectional & {$[68 \bullet \bullet]$} \\
\hline Cholesterol & $\mathrm{Yes}^{\mathrm{a}}$ & 1258 & Cross-sectional & [91] \\
\hline Cholesterol & Yes & 163 & Cross-sectional & {$[92]$} \\
\hline Cholesterol & No & 85 & Cross-sectional & [93] \\
\hline Cholesterol & No & 295 & Cross-sectional & [94] \\
\hline Triglycerides & No & 163 & Cross-sectional & {$[92]$} \\
\hline Triglycerides & Yes & 85 & Cross-sectional & [93] \\
\hline Triglycerides & No & 1258 & Cross-sectional & [91] \\
\hline Triglycerides & No & 295 & Cross-sectional & [94] \\
\hline Glucose & No & 1258 & Cross-sectional & [91] \\
\hline Glucose & No & 85 & Cross-sectional & [93] \\
\hline Glucose & No & 295 & Cross-sectional & [94] \\
\hline Glycated haemoglobin & Yes & 1258 & Cross-sectional & {$[91]$} \\
\hline Glycated haemoglobin & Yes & 61 & Cross-sectional & {$[95]$} \\
\hline Glycated haemoglobin & No & 295 & Cross-sectional & [94] \\
\hline Metabolic syndrome & Yes & 1258 & Cross-sectional & [91] \\
\hline Metabolic syndrome & Yes & 85 & Cross-sectional & [93] \\
\hline Diabetes & Yes & 3675 & Cross-sectional & {$[85]$} \\
\hline Diabetes & Yes & 760 & Cross-sectional & {$[96]$} \\
\hline Diabetes & Yes & 654 & Cross-sectional & {$[97]$} \\
\hline Diabetes & Yes & 283 & Cross-sectional & {$[84 \cdot]$} \\
\hline Diabetes & Yes & 55 & Cross-sectional & [98] \\
\hline Waist-hip ratio & Yes & $3202^{b}$ & Cross-sectional & {$[68 \bullet \bullet]$} \\
\hline Body mass index & Yes & $8062^{\mathrm{b}}$ & Cross-sectional & {$[68 \bullet \bullet]$} \\
\hline
\end{tabular}

${ }^{\mathrm{a}}$ Negative association

${ }^{\mathrm{b}}$ Meta-analysis

to their genetic make-up [29, 32]. Genome-wide association studies (GWAS) have documented associations between numerous single nucleotide polymorphisms (SNPs) and CVD [108] and have helped identify genetic variants in biomarkers that play a causal role in aetiology [109]. However, the largest GWAS meta-analysis of plasma cortisol to date has only identified three SNPs that were significantly associated with cortisol concentrations [110]. This result could be explained by the limitations of cortisol measurement in body fluids and the relatively small sample size of the study $(N=12,597)$. Despite low SNP-based heritability, a Mendelian randomisation study has found evidence consistent with a causal effect of plasma cortisol on CVD [111]. A GWAS meta-analysis of hair cortisol is currently underway. This work will help to elucidate the genetic basis of cortisol and provide reliable evidence for drug targets. Other studies have focused on the pathways through which stress may affect epigenetic regulation of individual HPA-axis genes and risk of stress-related disorders including CVD. Such work has demonstrated that DNA methylation of genes implicated in glucocorticoid regulation is linked with hypertension and subclinical atherosclerosis [112]. Future studies should seek to identify epigenome-wide DNA methylation associated with hair cortisol and examine their relationship with CVD.

\section{Conclusions}

The research discussed in this review contributes to the growing body of evidence suggesting that chronically elevated cortisol levels are not only implicated in the aetiology of CVD but also have modulating effects on its progression and treatment. The analysis of hair cortisol offers the opportunity to reliably assess long-term exposure to cortisol and examine its relationship with CVD and cardiometabolic risk factors (Fig. 1). Hair cortisol may be useful in studies of the effects of psychosocial, behavioural or pharmacological treatments on CVD prognosis. Unfortunately, the evidence available to date predominantly relies on relatively small cross-sectional 
studies, limiting the generalisability and reliability of the findings. Further studies employing longitudinal designs across larger samples of patients with CVD and healthy participants will have the potential to increase our understanding of the cardiovascular consequences of chronic cortisol excess and inform the development of more effective preventive and treatment interventions.

Funding Information E. Iob is supported by the ESRC-BBSRC Soc-B Centre for Doctoral Training (ES/P000347/1).

\section{Compliance with Ethical Standards}

Conflict of Interest Eleonora Iob and Andrew Steptoe declare that they have no conflict of interest.

Human and Animal Rights and Informed Consent This article is based on published research and does not contain any studies with human or animal subjects performed by any of the authors.

Open Access This article is distributed under the terms of the Creative Commons Attribution 4.0 International License (http:// creativecommons.org/licenses/by/4.0/), which permits unrestricted use, distribution, and reproduction in any medium, provided you give appropriate credit to the original author(s) and the source, provide a link to the Creative Commons license, and indicate if changes were made.

\section{References}

Papers of particular interest, published recently, have been highlighted as:

- Of importance

•- Of major importance

1. Ezzati M, Obermeyer Z, Tzoulaki I, Mayosi BM, Elliott P, Leon DA. Contributions of risk factors and medical care to cardiovascular mortality trends. Nat Rev Cardiol. 2015;12:508-30.

2. Naghavi M, Abajobir AA, Abbafati C, Abbas KM, Abd-Allah F, Abera SF, et al. Global, regional, and national age-sex specific mortality for 264 causes of death, 1980-2016: a systematic analysis for the Global Burden of Disease Study 2016. Lancet. 2017;390:1151-210.

3. World Health Organisation (2017) Cardiovascular diseases (CVDs). https://www.who.int/en/news-room/fact-sheets/detail/ cardiovascular-diseases-(cvds). Accessed 4 Jun 2019.

4. Lewington S, Whitlock G, Clarke R, Sherliker P, Emberson J, Halsey J, et al. Blood cholesterol and vascular mortality by age, sex, and blood pressure: a meta-analysis of individual data from 61 prospective studies with 55000 vascular deaths. Lancet. 2007;370:1829-39.

5. Lewington S, Clarke R, Qizilbash N, Peto R, Collins R. Agespecific relevance of usual blood pressure to vascular mortality: a meta-analysis of individual data for one million adults in 61 prospective studies. Lancet. 2002;360:1903-13.

6. Kivimäki M, Kuosma E, Ferrie JE, Luukkonen R, Nyberg ST, Alfredsson L, et al. Overweight, obesity, and risk of cardiometabolic multimorbidity: pooled analysis of individual-level data for
120813 adults from 16 cohort studies from the USA and Europe. Lancet Public Health. 2017;2:e277-85.

7. Sarwar N, Gao P, Seshasai S, et al. Diabetes mellitus, fasting blood glucose concentration, and risk of vascular disease: a collaborative meta-analysis of 102 prospective studies. Lancet. 2010;375:2215-22.

8. Mons U, Müezzinler A, Gellert C, et al. Impact of smoking and smoking cessation on cardiovascular events and mortality among older adults: meta-analysis of individual participant data from prospective cohort studies of the CHANCES consortium. BMJ. 2015;350:h1551.

9. Wahid A, Manek N, Nichols M, et al. Quantifying the association between physical activity and cardiovascular disease and diabetes: a systematic review and meta-analysis. J Am Heart Assoc. 2016;5: $\mathrm{e} 002495$.

10. World Health Organisation (2011) Global status report on alcohol and health. https://www.who.int/substance abuse/publications/ global_alcohol_report/msbgsruprofiles.pdf. Accessed 9 Jun 2019.

11. McEwen BS. Protective and damaging effects of stress mediators. N Engl J Med. 1998;338:171-9.

12. Hughes K, Bellis MA, Hardcastle KA, Sethi D, Butchart A, Mikton $\mathrm{C}$, et al. The effect of multiple adverse childhood experiences on health: a systematic review and meta-analysis. Lancet Public Health. 2017;2:e356-66.

13. Virtanen M, Kivimäki M. Long working hours and risk of cardiovascular disease. Curr Cardiol Rep. 2018;20:123.

14. Valtorta NK, Kanaan M, Gilbody S, Ronzi S, Hanratty B. Loneliness and social isolation as risk factors for coronary heart disease and stroke: systematic review and meta-analysis of longitudinal observational studies. Heart. 2016;102:1009-16.

15. Gan Y, Gong Y, Tong X, et al. Depression and the risk of coronary heart disease: a meta-analysis of prospective cohort studies. BMC Psychiatry. 2014;14:371.

16.• Kivimäki M, Steptoe A. Effects of stress on the development and progression of cardiovascular disease. Nat Rev Cardiol. 2017;15: 215-29 This is a comprehensive review about the role of stress in the pathogenesis and progression of CVD, mechanisms underlying this relationship, and prevention and treatment strategies focusing on stress reduction.

17. Arnold SV, Smolderen KG, Buchanan DM, Li Y, Spertus JA. Perceived stress in myocardial infarction: long-term mortality and health status outcomes. J Am Coll Cardiol. 2012;60:1756-63.

18. Celano CM, Millstein RA, Bedoya CA, Healy BC, Roest AM, Huffman JC. Association between anxiety and mortality in patients with coronary artery disease: a meta-analysis. Am Heart J. 2015; 170:1105-15.

19. Meijer A, Conradi HJ, Bos EH, Thombs BD, van Melle JP, de Jonge P. Prognostic association of depression following myocardial infarction with mortality and cardiovascular events: a metaanalysis of 25 years of research. Gen Hosp Psychiatry. 2011;33: 203-16.

20. Barth J, Schneider S, Von Känel R. Lack of social support in the etiology and the prognosis of coronary heart disease: a systematic review and meta-analysis. Psychosom Med. 2010;72:229-38.

21. Landsbergis PA, Dobson M, Koutsouras G, Schnall P. Job strain and ambulatory blood pressure: a meta-analysis and systematic review. Public Health. 2013;103:61-71.

22. Hackett RA, Steptoe A. Type 2 diabetes mellitus and psychological stress - a modifiable risk factor. Nat Rev Endocrinol. 2017;13:547-60.

23. Wardle J, Chida Y, Gibson EL, Whitaker KL, Steptoe A. Stress and adiposity: a meta-analysis of longitudinal studies. Obesity. 2011;19:771-8.

24. Fluharty MRes M, Taylor AE, Grabski MRes M, Munafò MR, Author C, Fluharty M. The Association of cigarette smoking with 
depression and anxiety: a systematic review. Nicotine Tob Res. 2017;19:3-13.

25. Fransson EI, Heikkilä K, Nyberg ST, et al. Systematic reviews and meta-and pooled analyses job strain as a risk factor for leisure-time physical inactivity: an individual-participant meta-analysis of up to 170,000 men and women the IPD-work consortium. Am J Epidemiol. 2012;176:1078-89.

26. Stalder T, Kirschbaum C. Analysis of cortisol in hair - state of the art and future directions. Brain Behav Immun. 2012;26:1019-29.

27. McEwen BS. Physiology and neurobiology of stress and adaptation: central role of the brain. Physiol Rev. 2007;87:873-904.

28. Aguilera G. The hypothalamic-pituitary-adrenal axis and neuroendocrine responses to stress. In: Pfaff $\mathrm{D}$, Levine J, editors. Fink G. Oxford: Handb. Neuroendocrinol. Academic Press; 2012. p. 175-96.

29. Girod J, Brotman D. Does altered glucocorticoid homeostasis increase cardiovascular risk? Cardiovasc Res. 2004;64:217-26.

30. Sapolsky RM, Romero LM, Munck AU. How do glucocorticoids influence stress responses ? preparative actions. Endocr Rev. 2000;21:55-89.

31. Whitworth JA, Williamson PM, Mangos G, Kelly JJ. Cardiovascular consequences of cortisol excess. Vasc Health Risk Manag. 2005;1:291-9.

32. Walker BR. Glucocorticoids and cardiovascular disease. Eur J Endocrinol. 2007;157:545-59.

33. Ullian M. The role of corticosteroids in the regulation of vascular tone. Cardiovasc Res. 1999;41:55-64.

34. Pivonello R, Isidori AM, De Martino MC, Newell-Price J, Biller BMK, Colao A. Complications of Cushing's syndrome: state of the art. Lancet Diabetes Endocrinol. 2016;4:611-29.

35. Lupoli R, Ambrosino P, Tortora A, Barba L, Lupoli GA, Di Minno MND. Markers of atherosclerosis in patients with Cushing's syndrome: a meta-analysis of literature studies. Ann Med. 2017;49: 206-16.

36. Wei L, MacDonald TM, Walker BR. Taking glucocorticoids by prescription is associated with subsequent cardiovascular disease. Ann Intern Med. 2004;141:764-70.

37. Turpeinen U, Hämäläinen E. Determination of cortisol in serum, saliva and urine. Best Pract Res Clin Endocrinol Metab. 2013;27: 795-801.

38. Russell E, Koren G, Rieder M, Van Uum S. Hair cortisol as a biological marker of chronic stress: current status, future directions and unanswered questions. Psychoneuroendocrinology. 2012;37: 589-601.

39. Adam EK, Kumari M. Assessing salivary cortisol in large-scale, epidemiological research. Psychoneuroendocrinology. 2009;34: 1423-36.

40. Reynolds RM, Labad J, Strachan MWJ, Braun A, Fowkes FGR, Lee AJ, et al. Elevated fasting plasma cortisol is associated with ischemic heart disease and its risk factors in people with type 2 diabetes: the Edinburgh type 2 diabetes study. J Clin Endocrinol Metab. 2010;95:1602-8

41. Nijm J, Kristenson M, Olsson AG, Jonasson L. Impaired cortisol response to acute stressors in patients with coronary disease. Implications for inflammatory activity. J Intern Med. 2007;262: 375-84.

42. Bhattacharyya MR, Molloy GJ, Steptoe A. Depression is associated with flatter cortisol rhythms in patients with coronary artery disease. J Psychosom Res. 2008;65:107-13.

43. Dekker MJHJ, Koper JW, van Aken MO, Pols HAP, Hofman A, de Jong FH, et al. Salivary cortisol is related to atherosclerosis of carotid arteries. J Clin Endocrinol Metab. 2008;93:3741-7.

44. Merswolken M, Deter H-C, Siebenhuener S, Orth-Gomér K, Weber CS. Anxiety as predictor of the cortisol awakening response in patients with coronary heart disease. Int J Behav Med. 2013;20:461-7.
45. Hamer M, Endrighi R, Venuraju SM, Lahiri A, Steptoe A. Cortisol responses to mental stress and the progression of coronary artery calcification in healthy men and women. PLoS One. 2012;7: e31356.

46. Barugh AJ, Gray P, Shenkin SD, MacLullich AMJ, Mead GE. Cortisol levels and the severity and outcomes of acute stroke: a systematic review. J Neurol. 2014;261:533-45.

47. Vogelzangs N, Beekman ATFF, Milaneschi Y, Bandinelli S, Ferrucci L, Penninx BWJHJH. Urinary cortisol and six-year risk of all-cause and cardiovascular mortality. J Clin Endocrinol Metab. 95:4959-64.

48. Kumari M, Shipley M, Stafford M, Kivimaki M. Association of diurnal patterns in salivary cortisol with all-cause and cardiovascular mortality: findings from the Whitehall II study. J Clin Endocrinol Metab. 2011;96:1478-85.

49. Adam EK, Quinn ME, Tavernier R, McQuillan MT, Dahlke KA, Gilbert KE. Diurnal cortisol slopes and mental and physical health outcomes: a systematic review and meta-analysis. Psychoneuroendocrinology. 2017;83:25-41.

50. Malan L, Schutte CE, Stranges S, Malan NT. Hypothalamicpituitary-adrenal-axis dysregulation and double product increases potentiate ischemic heart disease risk in a black male cohort: the SABPA study. Hypertens Res. 2017;40:590-7.

51. Liu H, Bravata DM, Cabaccan J, Raff H, Ryzen E. Elevated latenight salivary cortisol levels in elderly male type 2 diabetic veterans. Clin Endocrinol. 2005;63:642-9.

52. Hackett RA, Kivimäki M, Kumari M, Steptoe A. Diurnal cortisol patterns, future diabetes, and impaired glucose metabolism in the Whitehall II cohort study. J Clin Endocrinol Metab. 2016;101:619-25.

53. Hackett RA, Steptoe A, Kumari M. Association of diurnal patterns in salivary cortisol with type 2 diabetes in the Whitehall II study. J Clin Endocrinol Metab. 2014;99:4625-31.

54. Champaneri S, Xu X, Carnethon MR, Bertoni AG, Seeman T, Roux AD, et al. Diurnal salivary cortisol and urinary catecholamines are associated with diabetes mellitus: the multi-ethnic study of atherosclerosis. Metabolism. 2012;61:986-95.

55. Schoorlemmer RMM, Peeters GMEE, van Schoor NM, Lips P. Relationships between cortisol level, mortality and chronic diseases in older persons. Clin Endocrinol. 2009;71:779-86.

56. Hamer M, Steptoe A. Cortisol responses to mental stress and incident hypertension in healthy men and women. J Clin Endocrinol Metab. 2012;97:E29-34.

57. Rod NH, Kristensen TS, Diderichsen F, Prescott E, Jensen GB, Hansen AM. Cortisol, estrogens and risk of ischaemic heart disease, cancer and all-cause mortality in postmenopausal women: a prospective cohort study. Int J Epidemiol. 2010;39:530-8.

58. Reynolds RM, Ilyas B, Price JF, Fowkes FGR, Newby DE, Webb DJ, et al. Circulating plasma cortisol concentrations are not associated with coronary artery disease or peripheral vascular disease. QJM. 2009;102:469-75.

59. Smith GD, Ben-Shlomo Y, Beswick A, Yarnell J, Lightman S, Elwood P. Cortisol, testosterone, and coronary heart disease. Circulation. 2005;112:332-40.

60. Vreeburg SA, Kruijtzer BP, van Pelt J, van Dyck R, DeRijk RH, Hoogendijk WJG, et al. Associations between sociodemographic, sampling and health factors and various salivary cortisol indicators in a large sample without psychopathology. Psychoneuroendocrinology. 2009;34:1109-20.

61. van Ockenburg SL, Rosmalen JGM, Bakker SJL, de Jonge P, Gans ROB. Effects of urinary cortisol levels and resting heart rate on the risk for fatal and nonfatal cardiovascular events. Atherosclerosis. 2016;248:44-50.

62. Phillips AC, Carroll D, Gale CR, Lord JM, Arlt W, Batty GD. Cortisol, DHEA sulphate, their ratio, and all-cause and cause- 
specific mortality in the Vietnam experience study. Eur J Endocrinol. 2010;163:285-92.

63. Kunz-Ebrecht SR, Mohamed-Ali V, Feldman PJ, Kirschbaum C, Steptoe A. Cortisol responses to mild psychological stress are inversely associated with proinflammatory cytokines. Brain Behav Immun. 2003;17:373-83.

64. Reynolds RM, Walker BR, Haw S, Newby DE, Mackay DF, Cobbe SM, et al. Low serum cortisol predicts early death after acute myocardial infarction. Crit Care Med. 2010;38:973-5.

65. Incollingo Rodriguez AC, Epel ES, White ML, Standen EC, Seckl JR, Tomiyama AJ. Hypothalamic-pituitary-adrenal axis dysregulation and cortisol activity in obesity: a systematic review. Psychoneuroendocrinology. 2015;62:301-18.

66. Ragnarsson $\mathrm{O}$, Trimpou P, Oleröd G, Landin-Wilhelmsen $\mathrm{K}$. The association between urinary cortisol excretion and cardiovascular risk factors, bone status and quality of life in the population. Steroids. 2015;101:71-7.

67. Wright KD, Hickman R, Laudenslager ML. Hair cortisol analysis: a promising biomarker of HPA activation in older adults. Gerontologist. 2015;55:S140-5.

68.• Stalder T, Steudte-Schmiedgen S, Alexander N, Klucken T, Vater A, Wichmann S, et al. Stress-related and basic determinants of hair cortisol in humans: a meta-analysis. Psychoneuroendocrinology. 2017;77:261-74 This meta-analysis provides compelling evidence for the association of hair cortisol with systolic blood pressure, BMI, and waist-hip ratio, as well as with other stress-related determinants.

69. Raul J-S, Cirimele V, Ludes B, Kintz P. Detection of physiological concentrations of cortisol and cortisone in human hair. Clin Biochem. 2004;37:1105-11.

70. Fuchs A, Jaite C, Neukel C, Dittrich K, Bertsch K, Kluczniok D, et al. Link between children's hair cortisol and psychopathology or quality of life moderated by childhood adversity risk. Psychoneuroendocrinology. 2018;90:52-60.

71. Iob E, Kirschbaum C, Steptoe A. Positive and negative social support and HPA-axis hyperactivity : evidence from glucocorticoids in human hair. Psychoneuroendocrinology. 2018;96:100-8.

72. Khoury JE, Bosquet Enlow M, Plamondon A, Lyons-Ruth K. The association between adversity and hair cortisol levels in humans: a meta-analysis. Psychoneuroendocrinology. 2019;103:104-17.

73. Staufenbiel SM, Penninx BWJH, Spijker AT, Elzinga BM, van Rossum EFC. Hair cortisol, stress exposure, and mental health in humans: a systematic review. Psychoneuroendocrinology. 2013;38:1220-35.

74. Greff MJE, Levine JM, Abuzgaia AM, Elzagallaai AA, Rieder MJ, van Uum SHM. Hair cortisol analysis: an update on methodological considerations and clinical applications. Clin Biochem. 2019;63:1-9.

75. Ito N, Ito T, Kromminga A, Bettermann A, Takigawa M, Kees F, et al. Human hair follicles display a functional equivalent of the hypothalamic-pituitary-adrenal axis and synthesize cortisol. FASEB J. 2005;19:1332-4.

76. Kirschbaum C, Tietze A, Skoluda N, Dettenborn L. Hair as a retrospective calendar of cortisol production-increased cortisol incorporation into hair in the third trimester of pregnancy. Psychoneuroendocrinology. 2009;34:32-7.

77.•• Wester VL, van Rossum EFC. Clinical applications of cortisol measurements in hair. Eur J Endocrinol. 2015;173:M1-M10 This review discusses the applications of hair cortisol analysis in clinical practice and research and provides an overview of the evidence for the link between hair cortisol and cardiometabolic status.

78. Sauvé B, Koren G, Walsh G, Tokmakejian S, Van Uum SHM. Measurement of cortisol in human hair as a biomarker of systemic exposure. Clin Invest Med. 2007;30:E183-91.
79. Russell E, Kirschbaum C, Laudenslager ML, Stalder T, de Rijke Y, van Rossum EFC, et al. Toward standardization of hair cortisol measurement: results of the first international interlaboratory round robin. Ther Drug Monit. 2015;37:71-5.

80. Izawa S, Miki K, Tsuchiya M, Yamada H, Nagayama M. Hair and fingernail cortisol and the onset of acute coronary syndrome in the middle-aged and elderly men. Psychoneuroendocrinology. 2019;101:240-5 This article provides evidence for the association of hair cortisol with the incidence of acute coronary syndrome.

81. Pereg D, Gow R, Mosseri M, Lishner M, Rieder M, Van Uum S, et al. Hair cortisol and the risk for acute myocardial infarction in adult men. Stress. 2011;14:73-81 This article provides evidence for the association of hair cortisol with the incidence of acute myocardial infarction.

82. Colledge F, Brand S, Zimmerer S, Pühse U, Holsboer-Trachsler E, Gerber M. In individuals following aneurysmal subarachnoid haemorrhage, hair cortisol concentrations are higher and more strongly associated with psychological functioning and sleep complaints than in healthy controls hair cortisol in aSAH patients. Neuropsychobiology. 2017;75:12-20 This study provides evidence for elevated hair cortisol levels in patients who experienced aneurysmal subarachnoid haemorrhage. Additionally, it shows that patients with greater psychological distress have higher hair cortisol concentration.

83. Bossé S, D'Antono B, Stalder T. Childhood trauma, perceived stress, and hair cortisol in adults with and without cardiovascular disease. Psychosom Med. 2018;80:1 This study provides evidence for elevated hair cortisol concentrations in patients with coronary heart disease.

84. Manenschijn L, Schaap L, van Schoor NM, van der Pas S, Peeters GMEE, Lips P, et al. High long-term cortisol levels, measured in scalp hair, are associated with a history of cardiovascular disease. J Clin Endocrinol Metab. 2013;98:2078-83 This work demonstrates that higher cortisol levels are associated with both a history of CVD and diabetes in a population-based sample.

85. Abell JG, Stalder T, Ferrie JE, Shipley MJ, Kirschbaum C, Kivimäki M, et al. Assessing cortisol from hair samples in a large observational cohort: the Whitehall II study. Psychoneuroendocrinology. 2016;73:148-56 This study did not find evidence for the association between hair cortisol and CVD incidence in a large occupational cohort. However, hair cortisol was positively associated with BMI, diabetes, and CVD medication.

86. Pereg D, Chan J, Russell E, Berlin T, Mosseri M, Seabrook JA, et al. Cortisol and testosterone in hair as biological markers of systolic heart failure. Psychoneuroendocrinology. 2013;38:287582 This study provides evidence that elevated hair cortisol is associated with the severity of symptoms in a sample of patients with chronic heart failure.

87. Saleem M, Herrmann N, Swardfager W, Oh PI, Shammi P, Koren $\mathrm{G}$, et al. Higher cortisol predicts less improvement in verbal memory performance after cardiac rehabilitation in patients with coronary artery disease. Cardiovasc Psychiatry Neurol. 2013, 2013:18 This study shows that elevated hair cortisol levels predict poorer memory improvement in a sample of patients with coronary artery disease attending a one-year cardiac rehabilitation intervention.

88. Ben Assayag E, Tene O, Korczyn AD, et al. High hair cortisol concentrations predict worse cognitive outcome after stroke: results from the TABASCO prospective cohort study. Psychoneuroendocrinology. 2017;82:133-9 This work demonstrates that higher hair cortisol concentration in stroke patients is associated with larger lesion volume and worse cognitive results 6, 12 and 24 months following stroke. 
89. Dowlati Y, Herrmann N, Swardfager W, Thomson S, Oh PI, Van Uum S, et al. Relationship between hair cortisol concentrations and depressive symptoms in patients with coronary artery disease. Neuropsychiatr Dis Treat. 2010;6:393-400.

90. Younge JO, Wester VL, van Rossum EFC, Gotink RA, Wery MF, Utens EMWJ, et al. Cortisol levels in scalp hair of patients with structural heart disease. Int J Cardiol. 2015;184:71-8 This investigation provides evidence that worse subjective physical health status and higher respiratory rate are associated with elevated hair cortisol in patients with structural heart disease. Moreover, it shows that psychological treatment and greater psychological functioning lead to a decline in hair cortisol at 12-week follow-up.

91. Stalder T, Kirschbaum C, Alexander N, Bornstein SR, Gao W, Miller R, et al. Cortisol in hair and the metabolic syndrome. J Clin Endocrinol Metab. 2013;98:2573-80.

92. Mazgelytė E, Karčiauskaitė D, Linkevičiūtė A, Mažeikienė A, Burokienė N, Matuzevičienè R, et al. Association of hair cortisol concentration with prevalence of major cardiovascular risk factors and allostatic load. Med Sci Monit. 2019;25:3573-82.

93. Kuehl LK, Hinkelmann K, Muhtz C, Dettenborn L, Wingenfeld $\mathrm{K}$, Spitzer C, et al. Hair cortisol and cortisol awakening response are associated with criteria of the metabolic syndrome in opposite directions. Psychoneuroendocrinology. 2015;51:365-70.

94. Wester VL, Noppe G, Savas M, van den Akker ELT, de Rijke YB, van Rossum EFC. Hair analysis reveals subtle HPA axis suppression associated with use of local corticosteroids: the lifelines cohort study. Psychoneuroendocrinology. 2017;80:1-6.

95. Lehrer HM, Dubois SK, Maslowsky J, Laudenslager ML, Steinhardt MA. Hair cortisol concentration and glycated hemoglobin in African American adults. Psychoneuroendocrinology. 2016;72:212-8.

96. Staufenbiel SM, Penninx BWJH, de Rijke YB, van den Akker ELT, van Rossum EFC. Determinants of hair cortisol and hair cortisone concentrations in adults. Psychoneuroendocrinology. 2015;60:182-94.

97. Feller S, Vigl M, Bergmann MM, Boeing H, Kirschbaum C, Stalder T. Predictors of hair cortisol concentrations in older adults. Psychoneuroendocrinology. 2014;39:132-40.

98. Henley P, Jahedmotlagh Z, Thomson S, Hill J, Darnell R, Jacobs $\mathrm{D}$, et al. Hair cortisol as a biomarker of stress among a first nation in Canada. Ther Drug Monit. 2013;35:595-9.

99. Richards SH, Anderson L, Jenkinson CE, Whalley B, Rees K, Davies P, et al. Psychological interventions for coronary heart disease. Cochrane Database Syst Rev. 2017. https://doi.org/10. 1002/14651858.CD002902.pub4.
100. Moraes LJ, Miranda MB, Loures LF, Mainieri AG, Helena Mármora CC. A systematic review of psychoneuroimmunologybased interventions. Heal Med. 2018;23:635-52.

101. Twohig-Bennett C, Jones A. The health benefits of the great outdoors: a systematic review and meta-analysis of greenspace exposure and health outcomes. Environ Res. 2018;166:628-37.

102. Pascoe MC, Thompson DR, Jenkins ZM, Ski CF. Mindfulness mediates the physiological markers of stress: systematic review and meta-analysis. J Psychiatr Res. 2017;95:156-78.

103. Pascoe MC, Thompson DR, Ski CF. Yoga, mindfulness-based stress reduction and stress-related physiological measures: a meta-analysis. Psychoneuroendocrinology. 2017;86:152-68.

104. Barahona M-J, Valassi E, Webb SM. Adrenal gland hormones and the vascular system. In: PanVascular Med. Berlin, Heidelberg: Springer; 2015. p. 4641-51.

105. Goldberg SB, Manley AR, Smith SS, Greeson JM, Russell E, Van Uum S, et al. Hair cortisol as a biomarker of stress in mindfulness training for smokers. J Altern Complement Med. 2014;20:630-4.

106. Steptoe A, Easterlin E, Kirschbaum C. Conscientiousness, hair cortisol concentration, and health behaviour in older men and women. Psychoneuroendocrinology. 2017;86:122-7.

107. Larkin KT. Stress and hypertension. Yale: Yale University Press; 2005.

108. Hughes MF, Lenighan YM, Godson C, Roche HM. Exploring coronary artery disease GWAs targets with functional links to immunometabolism. Front Cardiovasc Med. 2018;5:148.

109. Bennett DA, Holmes MV. Mendelian randomisation in cardiovascular research: an introduction for clinicians. Heart. 2017;103: 1400-7.

110. Bolton JL, Hayward C, Direk N, Lewis JG, Hammond GL, Hill LA, et al. Genome wide association identifies common variants at the SERPINA6/SERPINA1 locus influencing plasma cortisol and corticosteroid binding globulin. PLoS Genet. 2014;10:e1004474.

111. Crawford A, Timpson N, Davey Smith G, Walker B. 19 testing causality in the association of plasma cortisol with risk of coronary heart disease: a Mendelian randomisation study. Heart. 2015;101: A6.4-A7.

112. Argentieri MA, Nagarajan S, Seddighzadeh B, Baccarelli AA, Shields AE. Epigenetic pathways in human disease: the impact of DNA methylation on stress-related pathogenesis and current challenges in biomarker development. EBioMedicine. 2017;18: $327-50$.

Publisher's Note Springer Nature remains neutral with regard to jurisdictional claims in published maps and institutional affiliations. 